See discussions, stats, and author profiles for this publication at: https://www.researchgate.net/publication/349636724

Content analysis of living historical memory around the world: Terrorization of the Anglosphere, and national foundations of hope in developing societies

Article in Memory Studies · February 2021

DOI: $10.1177 / 1750698021995974$

\section{CITATIONS}

0

4 authors:

Sarah Choi

Massey University

3 PUBLICATIONS 4 CITATIONS

SEE PROFILE

Silvia Mari

Università degli Studi di Milano-Bicocca

42 PUBLICATIONS 418 CITATIONS

SEE PROFILE

Some of the authors of this publication are also working on these related projects:

Project Article View project

Project Civil Service View project

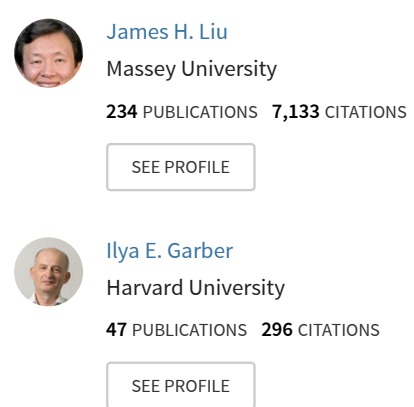




\title{
Content analysis of living historical memory around the world: Terrorization of the Anglosphere, and national foundations of hope in developing societies
}

Memory Studies

$1-19$

(C) The Author(s) 2021

Article reuse guidelines: sagepub.com/journals-permissions DOI: I0.1I77/I750698021995974 journals.sagepub.com/home/mss

@SAGE

\section{Sarah Y Choi}

Massey University, New Zealand

\section{James H Liu}

Massey University, New Zealand

\section{Silvia Mari iD}

University of Milano-Bicocca, Italy

\section{Ilya E Garber}

Harvard University, USA

Saratov State University, Russia

\begin{abstract}
Recently, researchers have endeavored to extend cultural perspectives of collective remembering by examining communicative or living historical memory (collective memories that emerge from informal communication between ordinary people). The current study examined the content and subjective evaluation of living historical memory from open-ended nominations of historical events provided by samples from 39 societies. Results showed that Western societies were dominated by living memories of terrorism, reflecting a distinctly negative climate. By contrast, many developing societies displayed a more positive climate in living memory that was rooted in events related to their nation's foundation. The current study opens up avenues for conceptualizing the role of collective remembering in shaping emotional climates that influence (or may be part of) national political culture.
\end{abstract}

\section{Keywords}

collective memory, content analysis, cross-cultural analysis, emotional climate, living historical memory, social representations of history

\section{Corresponding author:}

Sarah Choi, School of Psychology, Massey University, Level 3, North Shore Library Building, Private Bag 102904 , Auckland 0745, New Zealand.

Email: sarahchoi375@gmail.com 
"The past is never dead. It's not even past."

William Faulkner, "Requiem for a Nun” (1951)

This study documents a cross-cultural investigation of the relationship between the content and subjective evaluation of living historical memory across 39 societies (38 countries and the special administrative region of Hong Kong). Data was provided by open-ended but concise nominations of impactful historical events in living memory, which were then subjected to a cross-cultural content analysis. By examining what is collectively remembered in living historical memory across nations and how people feel about these memories, this study probes how living historical memory may relate to the emotional climate of a society.

\section{Social representations of history and collective remembering}

Psychological research on social representations of history (SRH) investigates the content and functional implications of socially shared knowledge and beliefs about the past (Liu and Hilton, 2005). According to this perspective, representations of history provide a symbolic reserve of historical content (i.e. shared meanings), that can be mobilized by political leaders to legitimize their political agendas (Liu and Hilton, 2005; Pennebaker and Banasik, 1997). Under this approach, collective memories can be defined as "individual memories shared by members of a community that bear on the collective identity of that community" (Hirst et al., 2018: 439).

This extends work done on collective remembering in sociology (see Olick et al., 2011) and history (Hobsbawm and Ranger, 2012), where researchers focus more on how shared memories of the past are shaped by institutional and cultural propagation. In such an approach, collective memories can be understood as "publicly available symbols maintained by society" (Hirst et al., 2018: 439). This has been termed cultural memory by Assman and Czaplicka (1995), in contrast to communicative memory, which is more informal and interpersonally constructed.

There has been growing interest in the integration of cultural and communicative/social memories (Hewer and Roberts, 2012; Kansteiner, 2002; Olick, 1999); as a focus on cultural and institutional mnemonic practices appears incomplete without also considering how such practices are realized and received in everyday communication. Furthermore, while much attention has focused on how collective remembering might build the political culture of a nation (Hilton and Liu, 2017), little research has examined how it might contribute to emotional climate: the dominant emotions experienced or perceived by members of a society in response to shared events (De Rivera, 1992).

\section{Living historical memory}

Following Assmann's (2011) idea of communicative/social memory, living historical memory (LHM: Liu et al., in press) refers to representations of historical events with impact on society that have occurred within the lifetimes of people living, or still personally remembered today. ${ }^{1}$ Such memories are thought to last up to three generations (Rimé et al., 2015; Stone et al., 2014), or a period of 80-100 years (Assmann, 2011), after which they may become institutionalized as part of cultural memory (or forgotten).

New events are constantly entering into living historical memory (like $9 / 11$, or the current COVID-19 pandemic), inscribed into public discourse through informal and communicative (as opposed to official and state-produced) processes, especially mass media. These processes facilitate the communal sharing of events, as was the case of reactions to the September 11th terror 
bombing (Powell, 2011; Woods, 2011). Such events may be collectively forgotten as the people who experienced it pass away (like the Korean War in the USA, see Schuman and Scott, 1989), or they may come to be institutionally embedded, as appears to be the case for World War II.

Similar concepts have been explored, such as "lived historical memory," which refers to "historical memories that unfold during one's life" (Muller et al., 2018: 974). Other concepts like flashbulb memories also involve vivid autobiographical memories of historical events (see Hirst et al., 2018 for a review). A key difference of living historical memory is that it is a communicative concept that includes both historical events that unfold during one's lifetime, and also those experienced in the lifetimes of people one has known. Therefore, living historical memory also includes historical events that are indirectly remembered through inter-generational communication, rather than just first-hand experiences. Such memories are still "alive" in present discourses through continued social sharing.

More broadly, these are conceptualized as personalized memories of public events, rather than personal memories (of private events, like the birth of one's child). Previous research has demonstrated how personalized memories of historical events can carry profound cognitive and emotional significance (e.g. Brown et al., 2009; Hirst et al., 2015). When distributed across many people, this kind of shared resonance can have major implications for collective phenomena. For example, Páez et al. (2016) demonstrated how individuals' collective recall of World War II predicted their willingness to fight for their country in current conflicts. There is thus an important place for the personalized sharing of collective events as an important part of the emotional climate of a society (see Páez et al., 2007).

\section{Living historical memory and emotional climate}

Emotional climates are theorized to be generated by people communicating with each other about their emotional responses to shared events, as this social sharing builds emotional convergence (De Rivera and Páez, 2007; Rimé, 1997; Schneider and Reichers, 1983). Thus, communicative processes not only inscribe LHM, but also form emotional climates. For example, exposure to communication about collective violence reinforces a certain subjective interpretation of events that fosters a climate of fear (De Rivera and Páez, 2007).

It is important to note how such emotional climates have the potential to influence enduring political culture, that is, the "political system as internalized in the cognitions, feelings, and evaluations of its population" (Almond and Verba, 1963: 14). Enduring national and political culture exists in a dynamic relationship with the prevailing emotional climate, which appears to have a life of its own, influenced as it is by mass communication about incoming events (Schneider and Reichers, 1983). Cultural norms may or may not be followed by new generations (Schuman and Scott, 1989), as new LHM and their emotional resonances can gradually change the emotional climate of society (e.g. Cohn et al., 2004). In this way, social sharing of events usually helps to maintain an enduring national culture; but also has the potential to destabilize/ reshape it.

\section{The present study}

We operationalize LHM as aggregates of historical memories that have been lived and/or communicated and shared amongst ordinary people today. Going beyond Liu et al.'s (in press) study that quantitatively examined LHM counts in relation to political attitudes, the current study investigates the qualitative content of LHM, and their corresponding evaluations (in terms of positive/negative valence). Content was analyzed by grouping historical events into categories like warfare, economics, 
or terrorism, rather than detailing specific events which were too numerous and idiosyncratic to compare across 39 societies. Furthermore, their corresponding evaluations provided indications of how these events were subjectively interpreted by individuals to produce an overall climate of positivity/ negativity.

Emotional climate researchers typically focus on dominant emotions either as an aggregate of the emotion itself (Fernández-Dols et al., 2007) or as an aggregate of how they are perceived (Páez et al., 2007); the approach taken here resembles the former. We also focus on affective valence (see also Honk and Schutter, 2006), which provides a simple approach to comparing emotional climates across 39 societies.

While no study to our knowledge has examined LHM across a wide sample of nationalities/ societies, there have been studies investigating social representations of world history across cultures (Liu et al., 2005, 2009). Across these studies, representations of world history were consistently Eurocentric and revolved around themes of politics and war. Nominations of the World Wars were the most dominant, especially WWII. The main difference here is a tighter focus on representations of national histories that are shared through informal communication, rather than including more input from history education. Nevertheless, we can still make some broad predictions based on past findings. For one, we expect high nominations of WWII, as it still falls (barely) within the window of living memory (having been experienced by some grandparents and great-grandparents, living and/or remembered today). If there is continuity in the Eurocentrism witnessed in earlier studies (Liu et al., 2005, 2009), we might also expect to see more positive evaluations of WWII (and related events of democratization) in the LHM of the victorious Western allies, compared to the Axis or neutral countries. ${ }^{2}$

On the other hand, some memory studies have started to show emergent narratives of decline in these same Western societies (Yamashiro and Roediger, 2019). As hinted by Liu et al. (2009), we may expect events related to terrorism to come to dominate LHM as WWII begins to die out, especially in societies where such coverage is dominant in mass media (Araújo et al., 2020; Powell, 2011; Savigny, 2016; Woods, 2011). This in turn, may be associated with more affectively negative evaluations of LHM, as many studies have demonstrated negative psychological responses to mass media portrayals of terrorism (e.g. Schuster et al., 2001; Silver et al., 2002).

We expect to find much greater nationalism than Eurocentrism across the board, given the study's focus on national histories. Furthermore, we expect to find more nominations of events that are foundational to the nation in societies that achieved official statehood relatively recently. This makes sense from a state-building perspective, which argues that there should be stronger motivation for newer states to construct justifications for their state and a national identity separate from their colonizers (see Cabecinhas et al., 2011). Thus, their LHM may be more influenced by a nationalist agenda (van de Bildt, 2015). Furthermore, there is less separation in time between cultural and living memory for these societies with recent statehood, and this may lead to more positive evaluations of LHM. Liu et al. (2009) found ethnocentrism in collective remembering to be most exaggerated and exceptionally positive in East Timor, the youngest state in the world at the time.

On the other hand, developing societies that have been experiencing political and economic instability in recent times may be preoccupied with recent memories of such instability and perhaps corruption. Indeed, Liu et al. (in press) found higher nominations of LHM to predict a more critical orientation to current political systems, especially in less socio-economically developed societies. Therefore, it is possible that developing societies, including many post-colonial societies governed by younger states, will actually report more negative evaluations of LHM, reflecting recent political/economic issues. 


\section{Method}

\section{Administration and translation}

The surveys used were part of a large-scale, international study examining a variety of social and political attitudes (The Digital Influence II project, see Liu et al., in press). These online surveys were administered in 42 societies from December 6th, 2018 to January 24th, 2019. They were administered in the dominant language of each respective society, except in the three African societies, where many different languages are spoken and thus it was advised that English would provide the best option. A large coalition of researchers, including at least two from each language group translated the survey from English to their home language using either the committee method (Brislin, 1980) or back-translation (Behling and Law, 2000).

\section{Participants and procedure}

Participants in the online study were recruited through the Harris Panel curated by the international polling firm Nielsen. Participants were stratified by age, gender, and income. They were invited by local panel providers through email or were given access to the survey link through an online portal. In total, 27,527 participants answered the survey. To ensure data quality, approximately $10 \%$ of cases were deleted for showing signs of non-attentive responding (for exclusion criteria, see supplementary materials). The total sample after deletions included 23,999 participants from 42 societies. Turkey, Mexico and Peru were not included due to errors or lack of availability in coding historical data. Therefore, the final sample used for this study included 22,363 participants from 39 societies.

In terms of demographics, a single item was used to assess political orientation: "On political issues, where would you place yourself on a scale of 0 to 10 ?" Answers ranged from 0 (strongly conservative) to 10 (strongly liberal). Subjective social status was assessed with the item: "On a scale of 1 to 10, with 10 being people who are the most well off in society, and 1 being the people who are least well off, where would you describe your position?" Level of education was assessed by asking: "What is the highest level of education you have completed?," with answers ranging from 1 (Elementary school) to 6 (Graduate school or higher). The overall sample was $50 \%$ female, varied in age between 18 and $89(M=36.71, \mathrm{SD}=12.39)$, was relatively well-educated $(M=4.34$, $\mathrm{SD}=1.14)$, relatively liberal $(M=6.42, \mathrm{SD}=2.59)$, and generally middle class in self-reported social status $(M=5.50, \mathrm{SD}=2.89)$, (see supplementary materials for age and gender proportions by country).

\section{Materials}

The open-ended item "Please name 3 historic events that have occurred during the lifetime of people you know (or have known) that have had the greatest impact on your country" was used. Participants were asked to write brief descriptions of their nominated events in the free blanks provided, together with their evaluations of the events on 1-7 scales ranging from very negative to very positive (see supplementary materials). Those events that were evaluated higher than midpoint (4), were interpreted as positive, while those evaluated below three were interpreted as negative, and those lying in between were interpreted as moderate. The average number of events nominated ranged between 1.16 in Bolivia and 2.21 in Kenya across the 39 samples (out of a maximum of $3, M=1.67, \mathrm{SD}=1.32$ ). The mean evaluation of all events ranged from 2.41 in Serbia to 5.13 in China $(M=3.95, \mathrm{SD}=1.74)$. 


\section{Coding}

Country-specific events were coded by local collaborators who had extensive knowledge about the historical events in their region. According to a general coding guideline that was used across the regions (see supplementary materials), just under half of participants $(42.8 \%)$ listed a total of three events that could be interpreted as historical. Around a quarter of participants (24.4\%) gave a combination of some historical and some non-historical responses, and just under a third of participants (32.8\%) listed no historical responses at all. Only historical responses were included for our content analysis.

Each of the historical nominations were coded, using codes for globally recognized historical events (e.g. WWII) and figures (e.g. Gandhi), as well as codes for country-specific events and figures (e.g. "1997 Handover" in Hong Kong). Lists of the most important and/or salient historical events and figures in living memory (those nominated by at least $5 \%$ of participants) were constructed and tallied for each country. This resulted in lists ranging from five nominations in Canada and India, to 13 nominations in Poland across the 39 samples (average $=8.13$ ). Over 300 events and figures were compiled on the final master list for all societies.

After refining coding instructions developed by Liu et al. $(2005,2009)$, events were then coded into one of the following categories: (a) terrorism (and related figures) (b) war (and related figures) (c) political events and figures (other than terrorism and war) (d) economic events and figures (e) disasters (f) scientific events and figures (g) sporting events and figures (h) cultural events and figures (i) crime-related events and figures. 96\% similarity was obtained between two independent coders. Only a few questions arose which were settled through discussion. Detailed coding instructions are provided in the supplementary materials.

\section{Results}

\section{Events in living historical memory}

Tables 1 and 2 show percentages of participant nominations for global and/or international events across different societies. As expected, WWII was nominated the most across societies. However, these were much less dominant compared to studies of world history (Liu et al., 2005, 2009). Only 13 out of 39 societies surveyed had WWII as part of their salient living memory, compared to 23 of 24 in the world history survey. Percentages of participants who nominated WWII ranged from $10 \%$ in the United States to $31 \%$ in Russia (for discussion of this variability, see Páez et al., 2016). This was followed by the September 11 th bombing, which was nominated by 10 societies, ranging from 5\% (Sweden, Pakistan, Spain) to 45\% (United States). This was followed by the 2008 global financial crisis and World War I, which were each nominated by five societies. Three societies had the Collapse of the Soviet Union and the Fall of the Berlin Wall as part of their top nominations. We note that these "consensual" events were nominated mostly in Western societies. They were much less salient in non-Western societies, a radical departure from the world history survey.

Table 3 shows percentages of participant nominations for nationally foundational events across different societies. Twelve out of 39 societies had a nationally foundational event as part of their salient living memory, with percentages of participant nominations ranging from $6 \%$ in Poland (Polish Independence) to $32 \%$ in Morocco (Moroccan Independence). Societies that nominated foundational events were predominantly non-Western and non-European, and as expected, tended to be those with more recent official statehood. We obtained official founding dates for the current state of each society from a list in the World Factbook Archive (Central Intelligence Agency [CIA], 2020). ${ }^{3}$ According to these, only Poland, Finland, and South Africa nominated a foundational event while having an official founding date that is more than 100 years old, although we note that the 
Table I. Percentages of participants who nominated the world wars and related events.

\begin{tabular}{|c|c|c|c|c|c|}
\hline \multicolumn{2}{|l|}{ WWI } & \multicolumn{2}{|l|}{ WWII } & \multicolumn{2}{|l|}{ Democratization } \\
\hline Country & $\%$ & Country & $\%$ & Country & $\%$ \\
\hline Netherlands & 23 & Russia & 31 & Collapse of the Soviet Union & \\
\hline New Zealand & 6 & United Kingdom & 29 & Russia & 34 \\
\hline Serbia & 6 & Poland & 24 & Poland & 21 \\
\hline United Kingdom & 6 & Serbia & 23 & Finland & 8 \\
\hline \multirow[t]{9}{*}{ Italy } & 5 & Hungary & 21 & & \\
\hline & & Italy & 21 & Fall of the Berlin Wall & \\
\hline & & New Zealand & 19 & Germany & 36 \\
\hline & & Canada & 17 & Finland & 12 \\
\hline & & Greece & 16 & Italy & 7 \\
\hline & & Australia & 15 & & \\
\hline & & Japan & 14 & & \\
\hline & & Sweden & 14 & & \\
\hline & & USA & 10 & & \\
\hline
\end{tabular}

Nominations for WWII in Russia includes nominations of the Great Patriotic War, which refers to the phase of WWII after Germany invaded the Soviet Union.

Table 2. Percentages of participants who nominated international 2 Ist century events.

\begin{tabular}{|c|c|c|c|}
\hline \multicolumn{2}{|c|}{ September IIth bombing } & \multicolumn{2}{|c|}{2008 financial crisis } \\
\hline Country & $\%$ & Country & $\%$ \\
\hline United States & 45 & Hungary & 11 \\
\hline Canada & 24 & Portugal & II \\
\hline Australia & 19 & Spain & 10 \\
\hline United Kingdom & 12 & Netherlands & 6 \\
\hline Netherlands & 9 & Singapore & 5 \\
\hline Italy & 7 & & \\
\hline Portugal & 6 & & \\
\hline Spain & 5 & & \\
\hline Pakistan & 5 & & \\
\hline Sweden & 5 & & \\
\hline
\end{tabular}

foundational event nominated in South Africa was the relatively recent 1994 Democracy/Freedom Day (signaling rebirth to a "Rainbow Nation").

\section{Subjective evaluation of living historical memory across cultures}

Figure 1 shows averaged evaluations of LHM across the 39 societies for salient events (events nominated by at least $5 \%$ of participants) and all events (all events nominated, including idiosyncratic responses). Interestingly, it appears that those societies with positive salient memories (averaging greater than the midpoint of 4), were predominantly from non-Western and non-European regions. These included four from South East Asia, two from Northern Africa and two from 
Table 3. Percentages of participants who nominated foundational events for their country.

Foundational events

\begin{tabular}{lr} 
Country & $\%$ \\
\hline Morocco & 32 \\
Kenya & 27 \\
South Africa & 21 \\
Singapore & 19 \\
Nigeria & 18 \\
Indonesia & 16 \\
India & 16 \\
Malaysia & 13 \\
China & 12 \\
Finland & 11 \\
Pakistan & 9 \\
Poland & 6 \\
\hline
\end{tabular}

Sub-Saharan Africa, along with one from East Asia, Latin America and South Asia. Most of these societies showed a tendency to nominate more positive events, especially China. That is, evaluations of their salient memories were more positive than the combined evaluation of all events.

By contrast, those societies with negative salient memories (averaging lower than 3-4), were generally those that were more socio-economically developed, except in some extreme cases (see Figure 1). Specifically, evaluations were most negative in Venezuela, ${ }^{4}$ followed by Serbia, ${ }^{5}$ after which there were four societies from Western (and Nordic) Europe, along with all five societies from the Anglosphere, three from Latin America, and one from East Asia. Here, we note consistently strong tendencies toward nominating negative events. This salience of negative memories appeared in a few societies experiencing material hardship and political instability, but mostly included societies that were prosperous and politically stable, like Sweden, Canada, and New Zealand.

Comparatively, those societies with a salience of positive living memories appeared to be younger (in official statehood). Only three out of the 14 societies displaying negative remembering had an official founding date within the last century, compared to 12 out of the 14 societies displaying positive remembering (see Figure 1). Moreover, averaged scores of the Human Development Index (HDI: United Nations Development Programme [UNDP], 2020) indicated that societies displaying positive remembering were less socio-economically developed (on average) than societies displaying negative remembering. A list of the societies with their respective HDI scores and official founding dates can be found in the supplementary materials.

Figure 2 shows this data with societies grouped into their respective regions. This figure shows a clear cultural gradation: Western and European regions were clustered together, followed by the Asian, and then the African regions. The Anglosphere showed the greatest tendency to remember negative events, while North Africa was the only region displaying a tendency to remember more positive events. Overall, these patterns suggest that it is surprisingly the more developed and stable societies that tended to evaluate events in LHM more negatively.

\section{The moderation of evaluation by content}

To contextualize these evaluations, we ought to connect them with patterns identified by a content analysis of events in LHM. Figure 3 shows percentages of event categories that emerged in the 


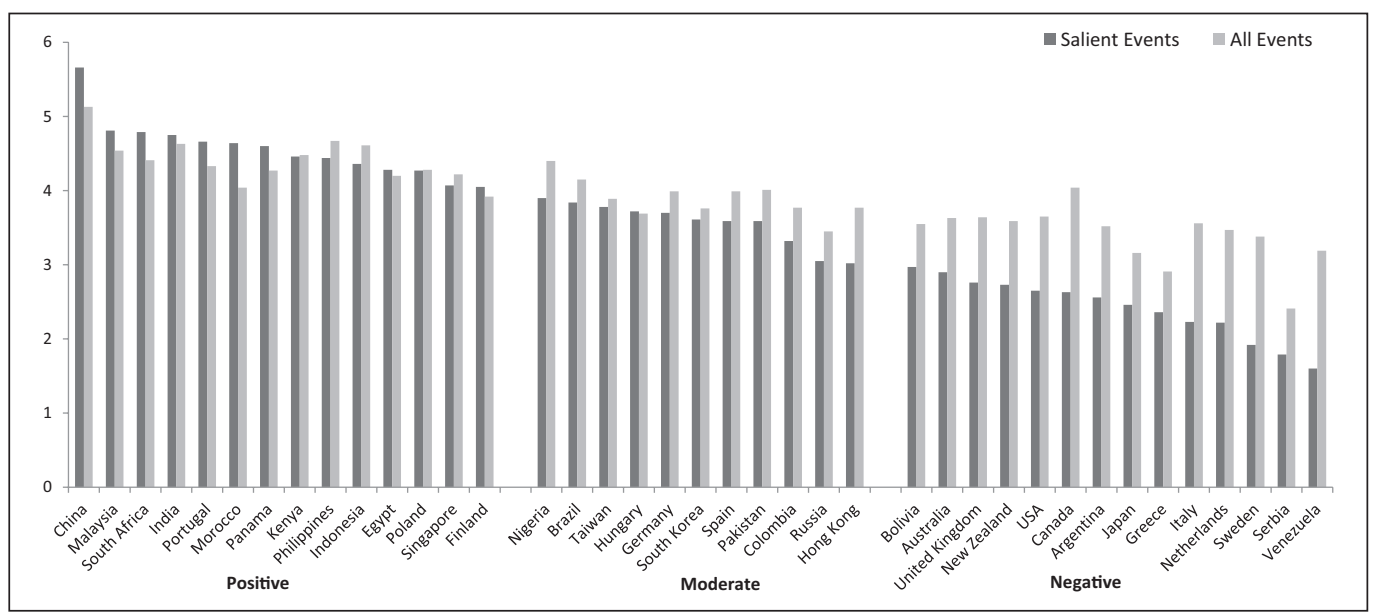

Figure I. Averaged evaluations of salient and all nominations across 39 societies.

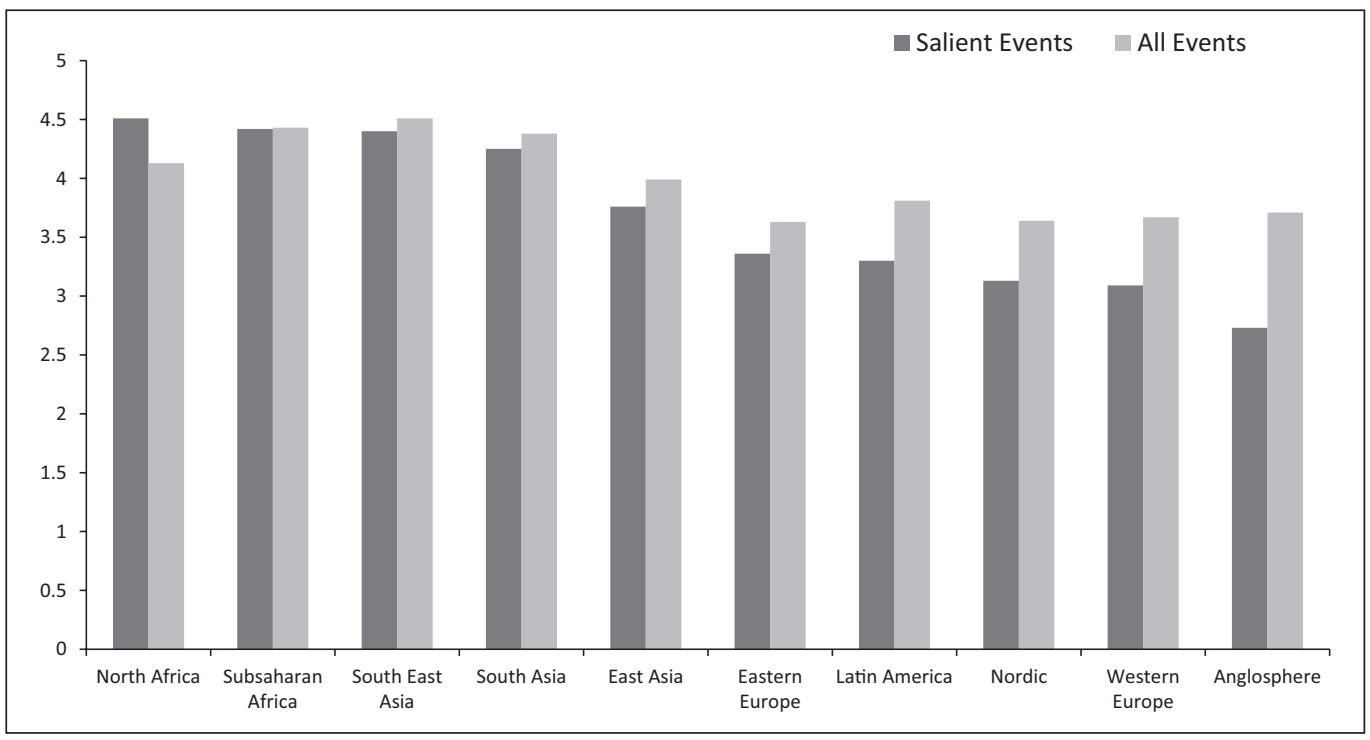

Figure 2. Averaged evaluations of salient and all nominations across regions.

salient living memory of each region. Detailed results of the content analysis for each country can be provided upon request. We report the following results in order, from regions with most negative to most positive remembering.

Anglosphere. The content analysis for societies of the Anglosphere (Australia, Canada, New Zealand, United Kingdom, United States) revealed how their negative evaluations were largely driven by high nominations of events related to terrorism (see Figure 3). Although their living memory was still a story of war $(29 \%)$ and politics $(29 \%)$, terrorism also emerged as a dominant theme overall (26\%). In all societies of this region, terrorism occupied more than $10 \%$ of salient memory. 
Furthermore, in four out of the five societies, terrorism was the most negatively evaluated category. ${ }^{6}$ Mean evaluations of terrorism did not exceed two for all societies $(M=1.75, \mathrm{SD}=1.27)$, while mean evaluations of war were less negative $(M=2.63, \mathrm{SD}=1.81)$. Evaluations of political nominations were more variable, with the overall mean being close to mid-point $(M=3.53, \mathrm{SD}=2.37)$.

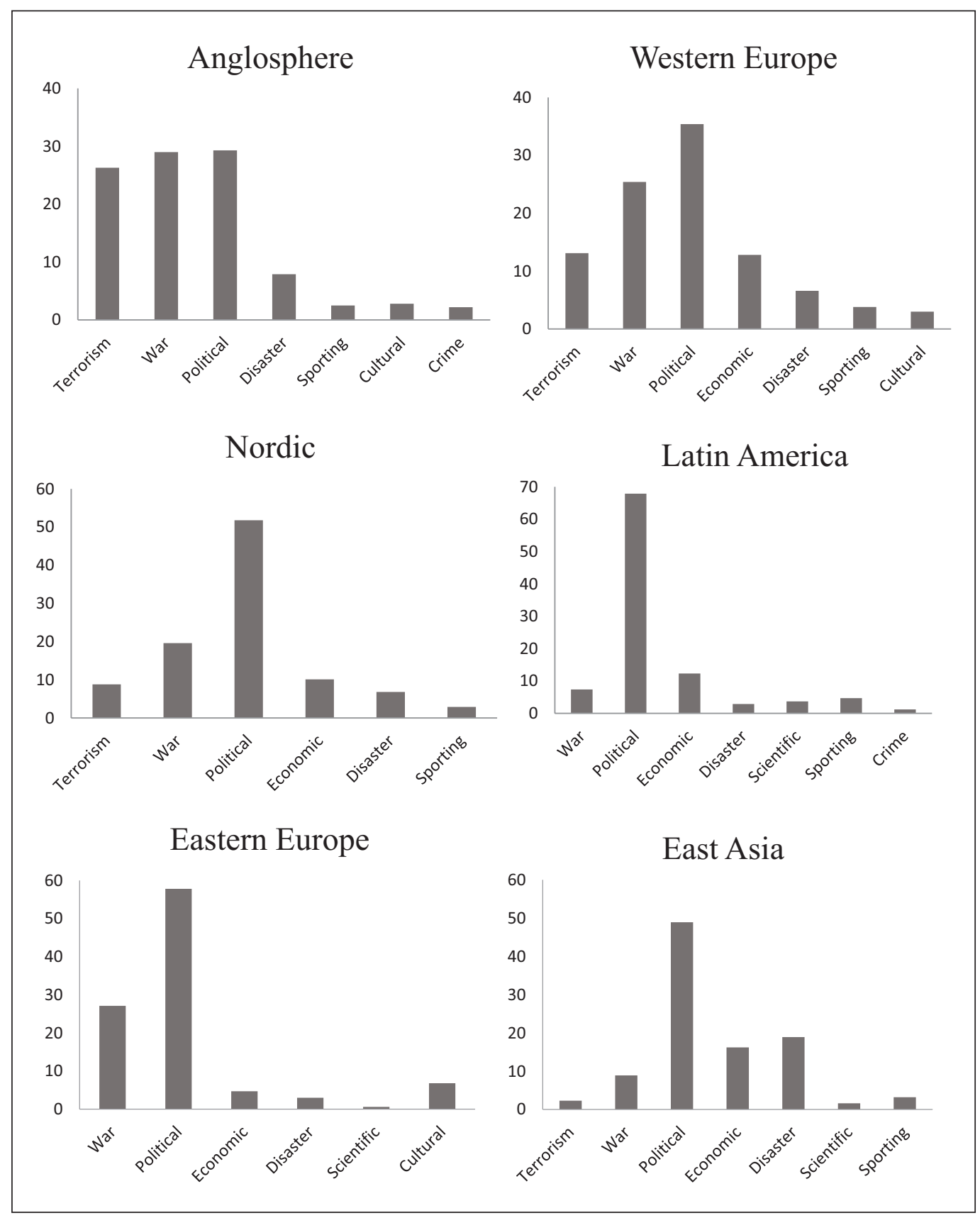

Figure 3. (Continued) 


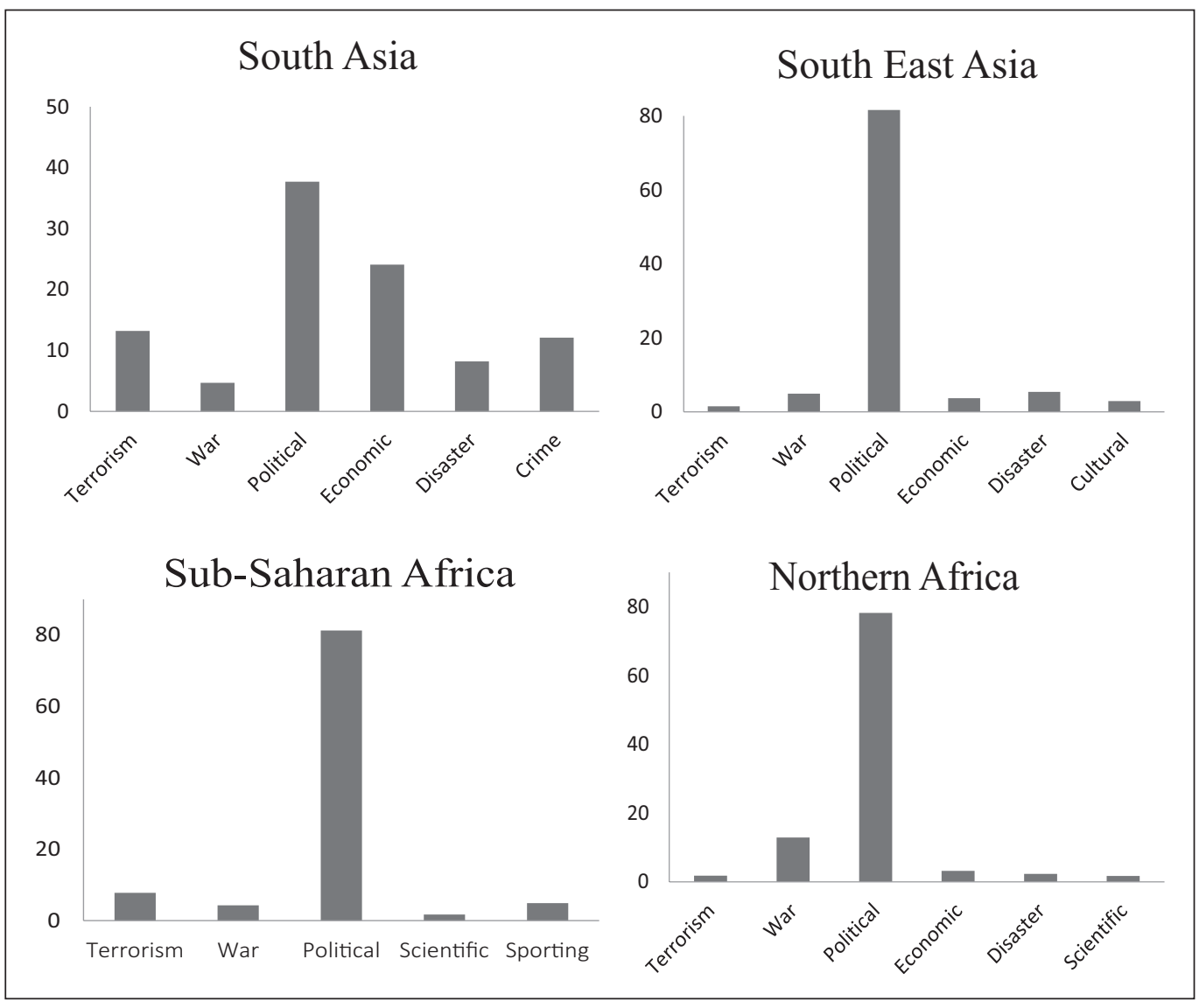

Figure 3. Percentages of salient content categories across regions.

Western Europe. LHM in Western Europe (Germany, Greece, Italy, Netherlands, Portugal, Spain) was predominantly a story of politics $(35 \%)$ and war $(25 \%)$, followed by economics in some societies and terrorism in others (see Figure 3). Political nominations were evaluated moderately positive overall $(M=4.7, \mathrm{SD}=2.36)$. This was followed by nominations of war, which were evaluated very negatively overall $(M=1.69, \mathrm{SD}=1.36)$; with particularly high nominations in Italy $(53 \%)$. Greece had particularly high economic nominations (34\%), which were also evaluated very negatively overall $(M=1.89, \mathrm{SD}=1.48)$. Thus, societies of Western Europe were haunted by negative memories of WWII and the 2008 global financial crisis. However, a smaller presence of terrorism (13\%) seemed to afford this region less negativity than the Anglosphere overall. Only the Netherlands had substantively large nominations of terrorism (29\%), which likely contributed to its greater negativity than others from this region (see Figure 1).

Nordic. The content of LHM across Sweden and Finland was vastly different, as reflected in their distant positions in Figure 1. Politics received the highest nominations, exceeding $40 \%$ in both societies but these nominations were evaluated more positively in Finland $(M=4.48$, $\mathrm{SD}=2.1$, at least partially owing to their positive memories of Finnish Independence. In contrast, Sweden's negativity seemed to stem from substantial nominations of terrorism $(21 \%)$, their 
most negatively evaluated category $(M=1.32, \mathrm{SD}=0.67)$, while Finland had no salient memories related to terrorism.

Eastern Europe. Political nominations were most common in the LHM of Eastern Europe (Hungary, Poland, Russia, Serbia), exceeding $30 \%$ of nominations in all societies ( $58 \%$ overall, see Figure 3). These were evaluated negatively in Serbia $(M=2.57, \mathrm{SD}=2.16)$, but quite moderately overall $(M=4.07, \mathrm{SD}=2.41)$. This was followed by nominations of war, which exceeded $10 \%$ of nominations in all societies ( $27 \%$ overall). Like Western Europe, this region seemed to be recovering from negatively remembered wars $(M=1.66, \mathrm{SD}=1.52)$, but this negativity was somewhat buffered by a complete absence of terrorism in salient memory. Poland's LHM contained foundational as well as cultural events related to the Pope, contributing to its positive position in Figure 1. A recently war-torn Serbia appeared on the extreme negative end of remembering.

Latin America. LHM in Latin America (Argentina, Bolivia, Brazil, Colombia, Panama, Venezuela) was also highly political, with political nominations exceeding $30 \%$ in all societies $(68 \%$ overall, see Figure 3$)$ and evaluated quite moderately overall $(M=3.43, \mathrm{SD}=2.5)$. This was followed by economic nominations (12\%). War was much less dominant compared to previous regions $(7 \%)$. Economic nominations were the most negatively evaluated out of the dominant categories $(M=1.79, \mathrm{SD}=1.64)$, thereby providing the main source of negativity for this region. However, this was somewhat buffered by low remembrances of war and an absence of terrorism in salient memory. Those societies with particularly high economic nominations, like Venezuela and Argentina, occupied the most negative positions of this region in Figure 1.

East Asia. LHM in East Asia (China, Japan, South Korea, Taiwan) was highly political in all societies except Japan (49\% overall, see Figure 3). This was followed by nominations of disaster (19\%) and economics (16\%). The main source of negativity for this region was disaster, as the most negatively evaluated category in four out of five societies $(M=1.93, \mathrm{SD}=1.5)$. Political nominations were moderately positive $(M=4.25, \mathrm{SD}=2.21)$, with mean evaluations exceeding four across all societies, except the SAR Hong Kong. Japan was the only country with considerable nominations of terrorism (10\%) and war (14\%). This, combined with exceptionally high nominations of disaster (37\%), placed Japan as the lowest of this region in Figure 1, followed by Hong Kong. China, with its positive evaluations of political $(M=5.55, \mathrm{SD}=2.18)$ and economic $(M=6.6, \mathrm{SD}=0.87)$ events, occupied the most positive position.

South Asia. In South Asia, there was a considerable amount of terrorism in LHM (13\%). However, this was not remembered as negatively as in the West $(M=2.14, \mathrm{SD}=1.88)$. Political nominations exceeded $25 \%$ in both societies (38\% overall) and were very positively evaluated $(M=6.16$, $\mathrm{SD}=1.55)$. This was followed by economic nominations in India (43\%), which were moderately evaluated $(M=3.91, \mathrm{SD}=2.15)$. In Pakistan, there were high nominations of crime $(28 \%)$, that were negatively evaluated $(M=2.8, \mathrm{SD}=2.46)$. Here, political memories seemed to provide a major buffer against negative memories of crime and terrorism, with both societies having nominated foundational events as part of their most salient and positive events in living memory.

South-East Asia. LHM in South-East Asia (Indonesia, Malaysia, Philippines, Singapore) was overwhelmingly political, with political nominations exceeding $70 \%$ in all societies $(82 \%$ overall, see Figure 3$)$. These were consistently evaluated as moderately positive $(M=4.74, \mathrm{SD}=2.19)$. Terrorism was only nominated by the Philippines (5\%), where it was not as negatively evaluated as in Western societies $(M=2.43, \mathrm{SD}=1.83)$. Like in Latin America, economic nominations seemed to 
provide the main source of negativity $(M=1.86, \mathrm{SD}=1.29)$. However, these were much less dominant, occupying only $4 \%$ of nominations overall. With low remembrances of war, terrorism, disaster, and economic issues, the LHM of South-East Asian societies was completely dominated by political nominations, which included positive foundational events for three out of the four societies (Singapore, Indonesia, and Malaysia).

Sub-Saharan Africa. Nominations were highly political in Sub-Saharan Africa (Nigeria, Kenya, South Africa), exceeding $70 \%$ of nominations in all societies ( $81 \%$ overall, see Figure 3$)$, followed by nominations of terrorism in Kenya (13\%) and Nigeria (12\%). Political nominations were consistently evaluated as moderately positive $(M=4.67, \mathrm{SD}=2.56)$. Terrorism was very negatively evaluated in Nigeria $(M=1.45, \mathrm{SD}=1.32)$ contributing to its lowest position of this region in Figure 1. However, these memories were still buffered by foundational memories of Nigerian independence. South Africa had highly salient memories of a foundational event (1994 Democracy Day). Combined with the absence of terrorism in salient memory, this placed the country above Kenya and Nigeria in Figure 1.

North Africa. Political nominations exceeded $70 \%$ in both societies of Northern Africa (78\% overall) and were evaluated as moderately positive $(M=4.51, \mathrm{SD}=2.23)$. This was followed by nominations of war in Egypt $(21 \%)$, which were positive $(M=5.48, \mathrm{SD}=2.24)$. Although LHM of Morocco included some (5\%) negative nominations of terrorism $(M=1.3, \mathrm{SD}=0.64)$, it still occupied a higher position than Egypt in Figure 1, due to having more positive political nominations. Indeed, Morocco had a foundational event (Moroccan independence) nominated as part of its salient memory while Egypt did not.

\section{Discussion}

The current study mapped and compared the living historical memory of 39 societies, by examining what is collectively being remembered (content) and how (evaluation). It appeared that LHM was predominantly a story of politics, especially in non-Western, non-European regions (i.e. Asia, Latin America, and Africa). In European regions, it was a story of politics and war; in the Anglosphere it was a story of politics, war, and terrorism. Negative collective remembering (see Figure 1) stemmed primarily from:

(1) Nominations of terrorism (Anglosphere societies, Netherlands, Sweden).

(2) Nominations of war (Serbia, Italy).

(3) Nominations of disaster (Japan).

(4) Nominations of economic (Venezuela, Greece, Argentina) and political (Bolivia) instability.

Positive collective remembering seemed to stem from events in the political domain, with a high degree of country-specificity in events. A major cluster of these were foundational events. Overall, this is a far less universal pattern than what was reported for the world history survey, where WWII dominated in almost all societies (Liu et al., 2005, 2009).

\section{Living memories of politics in developing, post-colonial societies}

Liu et al. (in press) showed how LHM functioned to bolster national identity while simultaneously enhancing critical evaluations against political systems, especially in developing nations. Such 
findings can be contextualized with our content analysis. On one hand, LHM of developing societies did indeed hold negative memories of political corruption (e.g. ANC corruption in South Africa), which may produce critical consciousness. At the same time, their political memories seemed to serve a nation-building function by also holding positive memories of national independence and social movements. While events like uprisings and protests were often violent and traumatic (e.g. Reformasi in Indonesia), these formative events seem to be remembered positively, perhaps as a source of empowerment for overcoming on-going corruption or dictatorship (see Vázquez and Páez, 2010).

Our results add support to the speculations raised by Liu et al. (in press), that such narratives in developing societies are less likely to be direct products of states "manufacturing consent." Rather, they seem to be propagated by the bottom-up needs and aspirational hopes of ordinary people (Cabecinhas et al., 2011), and their beliefs in national history as being progress-oriented (Páez et al., 2016). Living memories of national independence may provide a sense of hope and promise for many developing societies that people (who are still remembered or alive today) fought for. How long this climate of remembering will be retained, may depend on how such promises are fulfilled by political developments in the future, and how much longer communicative remembering of foundational events will last. In turn, developing societies without foundational memories appeared to be less protected from negative climates.

\section{Living memories of terrorism in the West}

Nominations of terrorism conferred a much more negative climate than nominations of war, even though both involve collective violence. Some emotional/psychological distance from war seems to have emerged, as war was less negatively evaluated overall compared to previous studies (Liu et al., 2005, 2009). It is worth questioning whether such distance is afforded simply by the passage of time and generations (Schuman and Scott, 1989), or by its displacement with new negative events in LHM.

One of the most striking and consistent findings was a distinct climate of negativity in the wealthy societies of the Anglosphere. Our findings suggest that these negative climates were rooted in living memories of terrorism. Interestingly, memories of terrorism were considerably more negative than memories of war and natural disasters in Western societies. Indeed, studies have shown collective stress (Schuster et al., 2001) and trauma (Silver et al., 2002) in response to portrayals of terrorism, but it is worth questioning why and how this differs from media portrayals of other negative events.

There seems to be something unique about how terrorism is communicated, at least in Western contexts, that goes beyond just saturation media coverage (see Araújo et al., 2020). It may be that on a deeper level, these events represent an erosion of economic and cultural power for Western societies. This symbolic threat that is publicly consolidated in living memory through channels like mass media, flowing into private social networks, may be at the root of what is cultivating negativity. The much higher salience of external threats of terrorism (e.g. 9/11, Manchester bombing), over local acts of collective violence (e.g. mass shootings) further speaks to the resonance of a deeper symbolic threat. Further discursive research is necessary for unpacking such claims.

By contrast, terrorism emerged less (and less negatively) in the living memory of South East Asian and African societies, even though it constitutes an objectively significant issue in some of these places (e.g. Nigeria, Indonesia). Instead, individuals prioritized memories of political events, particularly national independence and decolonization, producing a much less negative climate.

Cognitive explanations, such as recency effects, also deserve consideration (see also Liu et al., 2009). It is possible that the over-representation of terrorism reflects a greater recency or novelty 
of terrorism and related threats in more developed societies. Furthermore, given the nature of our probe, foundational events were inevitably excluded from nominations of most Western societies. The negativity that was observed may simply reflect this absence, rather than indicating a climate of decline over time (however, see Yamashiro and Roediger, 2019). Nonetheless, the finding that foundational events continue to be so salient in the living memory of many developing societies is noteworthy and ought to have important functional/political implications (see Liu et al., in press). Moreover, the finding that similar categories of events were evaluated substantially more negatively in developed compared to developing societies is suggestive of a greater tendency for them to remember more negatively.

\section{Toward a balanced model of collective remembering}

It is becoming increasingly apparent that collective memory research should consider the complex interplays between individual/interpersonal and cultural processes. Research in collective remembering has traditionally focused on collective memory as what Assmann and Czaplicka (1995) consider to be "objectivized culture." As part of recent efforts to illuminate the social/interpersonal processes involved in collective remembering, the current study showed how communicative memories of public events can be associated with unpredictable and/or destabilizing emotional climates. In line with social-interactionist perspectives (Schneider and Reichers, 1983), this showed massive disconnects; with LHM being acutely negative, while many aspects of material/structural reality are quite positive in most Western societies; and the exact opposite pattern manifesting in many developing societies. Only in certain extreme cases did negative climates appear to reflect material realities (i.e. Venezuela, Serbia, Greece).

With this updated perspective (see also Assmann, 2011; Hewer and Roberts, 2012; Hirst et al., 2018), the civic/political culture of a country (Almond and Verba, 1963) can be seen as not only bound to the past through culturally inscribed, and largely unchanging historical symbols, institutions, and ritualized practices, but also swayed by emotional climates that arise from the bottom up, through the communicative remembering of interacting generations. This may have become the case with terrorism in the Anglosphere, as the current study suggests that people of Englishspeaking societies are now living with post-9/11 rather than post-WWII representations of history (Liu et al., 2009). Having the "War against Terror" narrative embedded in informal discourse has significantly different (and less positive) implications compared to being "Champions" or "Defenders" of the "Free World" as in the aftermath of WWII (Araújo et al., 2020; Powell, 2011).

Such may also become the case with the current COVID-19 pandemic over time, where climates of fear and anxiety may be taking form in many societies as they consolidate these new events in living memory. Future research should use such opportunities to investigate the role of communicative remembering (and the emotional climates they produce) as sensitive early warning indicators of shifts in national political culture. This represents possibilities for significant theoretical advance, as the previous literature has more strongly emphasized the stabilizing rather than de-stabilizing properties of social representations of history (Liu and Sibley, 2009), and of collective remembering (Olick and Robbins, 1998).

\section{Limitations}

A significant limitation of our efforts to represent LHM around the world is the lack of data from Middle Eastern societies. Furthermore, by covering the LHM of 39 societies via broad content categories, we may have overlooked the more complex memory structures that exist within cultures. We acknowledge that the current study provides only general descriptive findings and thus, 
country-specific studies that incorporate the relevant historical and cultural backgrounds in their analysis are needed to contextualize these findings for deeper interpretation. For example, qualitative case studies may be able to examine emotional climates of LHM in greater depth, identifying culturally specific climates of fear versus hope (Bar-Tal, 2001). These could go beyond the survey methods used here to interface with the emerging literature in sociology (e.g. Gensburger, 2019) that looks at how communicative memory manifests in everyday life and ordinary places; and experiments in psychology that examine implicit relationships between autobiographical and historical memory (Brown et al., 2009). Moreover, it may be worth charting the different properties of communicative/living memories and lived/autobiographical memories of history. Memories that are learned through inter-generational communication may have important functional and qualitative differences to those that are observed from one's own lifetime. Finally, future research should continue to explore different probes of communicative memory in efforts to arrive at a stable and coherent measure that best reflects historical memory in everyday communication and cognition.

\section{Conclusion}

The current study investigated the content and evaluation of LHM across 39 societies. Our content analysis provided a cross-cultural sketch of the kind of events that have converged in the living memory of these diverse societies, and how these memories were subjectively evaluated. This indicated that living memories of terrorism were associated with a climate of negativity in Western societies, while living memories of national origins were associated with more positive climates across many developing societies. Tracking shifts in communicative remembering using more indepth, integrative methods across different societies and generations presents fruitful avenues for future research. These could provide insight into how specific processes of everyday social interaction feed into national political culture and its changes.

\section{Declaration of conflicting interests}

The author(s) declared no potential conflicts of interest with respect to the research, authorship, and/or publication of this article.

\section{Funding}

The author(s) disclosed receipt of the following financial support for the research, authorship, and/or publication of this article: This research was supported by Grant FA2386-15-1-0003 from the Asian Office of Aerospace Research and Development.

\section{ORCID iDs}

Sarah Y Choi (iD https://orcid.org/0000-0002-0498-9106

Silvia Mari (iD https://orcid.org/0000-0001-6543-5249

\section{Supplemental material}

Supplemental material for this article is available online.

\section{Notes}

1. Taken out of context of its contrast with cultural memory, Assmann's term "communicative memory" can be ambiguous, as it is a semantically broad term that could refer to memories of personal rather than historical events. So we use the term "living historical memory" for our research, but use communicative memory in reference to the larger literature. 
2. Positive memories of World War II may also be observed in Russia.

3. We acknowledge that these dates can be disputed.

4. Experiencing thousand percent inflation and political unrest.

5. Severely bombed by NATO in the Balkan Wars after the collapse of Yugoslavia.

6. In the USA, crime was evaluated slightly more negatively than terrorism, but it was much less salient.

\section{References}

Almond GA and Verba S (1963) The Civic Culture: Political Attitudes and Democracy in Five Nations. New Jersey: Princeton University Press.

Araújo RDCR, Vilar R, Liu JH, et al. (2020) Human values and ideological beliefs as predictors of attitudes toward immigrants across 20 countries: The country-level moderating role of threat. European Journal of Social Psychology 50(3): 534-546.

Assmann J (2011) Communicative and cultural memory. In: Meusburger P, Heffernan M and Wunder E (eds) Cultural Memories: The Geographical Point of View. Dordrecht: Springer, pp.15-27.

Assmann J and Czaplicka J (1995) Collective memory and cultural identity. New German Critique 65: 125133.

Bar-Tal D (2001) Why does fear override hope in societies engulfed by intractable conflict, as it does in the Israeli society? Political Psychology 22(3): 601-627.

Behling O and Law KS (2000) Translating Questionnaires and Other Research Instruments: Problems and Solutions. California: Sage Publications.

Brislin RW (1980) Translation and content analysis of oral and written materials. In: Triandis HC and Berry WC (eds) Handbook of Cross-Cultural Psychology. Boston: Allyn \& Bacon, pp.389-444.

Brown NR, Lee PJ, Krsiak M, et al. (2009) Living in history: How war, terrorism, and natural disaster affect the organization of autobiographical memory. Psychological Science 20(4): 399-405.

Cabecinhas R, Liu JH, Licata L, et al. (2011) Hope in Africa? Social representations of world history and the future in six African countries. International Journal of Psychology 46(5): 354-367.

Central Intelligence Agency (2020) World factbook archive. Available at: https://www.cia.gov/the-worldfactbook/countries/ (accessed 16 February 2021).

Cohn MA, Mehl MR and Pennebaker JW (2004) Linguistic markers of psychological change surrounding September 11, 2001. Psychological Science 15(10): 687-693.

De Rivera J (1992) Emotional climate: Social structure and emotional dynamics. In: Strongman KT (ed.) International Review of Studies on Emotion. Chichester: John Wiley \& Sons, pp.197-218.

De Rivera J and Páez D (2007) Emotional climate, human security, and cultures of peace. Journal of Social Issues 63(2): 233-253.

Fernández-Dols JM, Carrera P, De Mendoza AH, et al. (2007) Emotional climate as emotion accessibility: How countries prime emotions. Journal of Social Issues 63(2): 339-352.

Gensburger S (2019) Memory on My Doorstep: Chronicles of the Bataclan Neighborhood, Paris 2015-2016. Belgium: Leuven University Press.

Hewer CJ and Roberts R (2012) History, culture and cognition: Towards a dynamic model of social memory. Culture and Psychology 18(2): 167-183.

Hilton DJ and Liu JH (2017) History as the narrative of a people: From function to structure and content. Memory Studies 10(3): 297-309.

Hirst W, Phelps EA, Meksin R, et al. (2015) A ten-year follow-up of a study of memory for the attack of September 11, 2001: Flashbulb memories and memories for flashbulb events. Journal of Experimental Psychology: General 144(3): 604-623.

Hirst W, Yamashiro JK and Coman A (2018) Collective memory from a psychological perspective. Trends in Cognitive Sciences 22(5): 438-451.

Hobsbawm E and Ranger T (2012) The Invention of Tradition. Cambridge: Cambridge University Press.

Honk JV and Schutter DJ (2006) From affective valence to motivational direction: The frontal asymmetry of emotion revised. Psychological Science 17(11): 963-965.

Kansteiner W (2002) Finding meaning in memory: A methodological critique of collective memory studies. History and Theory 41(2): 179-197. 
Liu JH, Bou Zeineddine F, Choi SY, et al. (in press) Living historical memory: Associations of communicative and cultural memories with national identity, social dominance orientation, and system justification in 40 nations. Journal of Applied Research in Memory and Cognition, 17 January 2021. https://doi. org/10.1016/j.jarmac.2020.09.007

Liu JH, Goldstein-Hawes R, Hilton D, et al. (2005) Social representations of events and people in world history across 12 cultures. Journal of Cross-Cultural Psychology 36(2): 171-191.

Liu JH and Hilton DJ (2005) How the past weighs on the present: Social representations of history and their role in identity politics. British Journal of Social Psychology 44(4): 537-556.

Liu JH, Páez D, Slawuta P, et al. (2009) Representing world history in the 21st century: The impact of 9/11, the Iraq war, and the nation-state on dynamics of collective remembering. Journal of Cross-Cultural Psychology 40(4): 667-692.

Liu JH and Sibley CG (2009) Culture, social representations, and peacemaking: A symbolic theory of history and identity. In: Montiel C and Noor N (eds) Peace Psychology in Asia. New York, NY: Springer, pp.21-42.

Muller F, Bermejo F and Hirst W (2018) Cultural and communicative memories: Contrasting Argentina's 1976 coup d'état and the 2001 economic-political-social crisis. Memory 26(7): 974-984.

Olick JK (1999) Collective memory: The two cultures. Sociological Theory 17(3): 333-348.

Olick JK and Robbins J (1998) Social memory studies: From "collective memory" to the historical sociology of mnemonic practices. Annual Review of Sociology 24(1): 105-140.

Olick JK, Vinitzky-Seroussi V and Levy D (eds) (2011) The Collective Memory Reader. New York, NY: Oxford University Press.

Páez D, Basabe N, Ubillos S, et al. (2007) Social sharing, participation in demonstrations, emotional climate, and coping with collective violence after the March 11th Madrid bombings. Journal of Social Issues 63(2): 323-337.

Páez D, Liu JH, Bobowik M, et al. (2016) Social representations of history, cultural values, and willingness to fight in a war: A collective-level analysis in 40 nations. Asian Journal of Social Psychology 19(4): $347-361$.

Pennebaker JW and Banasik BL (1997) On the creation and maintenance of collective memories: History as social psychology. In: Pennebaker JW, Páez D and Rimé B (eds) Collective Memory of Political Events: Social Psychological Perspectives. New Jersey: Lawrence Erlbaum, pp.15-32.

Powell KA (2011) Framing Islam: An analysis of US media coverage of terrorism since 9/11. Communication Studies 62(1): 90-112.

Rimé B (1997) How individual emotional episodes feed collective memory. In: Pennebaker JW, Páez D and Rimé B (eds) Collective Memory of Political Events: Social Psychological Perspectives. New Jersey: Lawrence Erlbaum, pp.131-146.

Rimé B, Bouchat P, Klein O, et al. (2015) When collective memories of victimhood fade: Generational evolution of intergroup attitudes and political aspirations in Belgium. European Journal of Social Psychology 45(4): 515-532.

Savigny H (2016) Islam as a threat? Problematisation of Muslims in the mass media and effects on the political system. In: Marsden L and Savigny H (eds) Media, Religion and Conflict. London: Routledge, pp.83-104.

Schneider B and Reichers AE (1983) On the etiology of climates. Personnel Psychology 36(1): 19-39.

Schuman H and Scott J (1989) Generations and collective memories. American Sociological Review 54(3): 359-381.

Schuster MA, Stein BD, Jaycox LH, et al. (2001) A national survey of stress reactions after the September 11, 2001, terrorist attacks. New England Journal of Medicine 345(20): 1507-1512.

Silver RC, Holman EA, McIntosh DN, et al. (2002) Nationwide longitudinal study of psychological responses to September 11. JAMA 288(10): 1235-1244.

Stone CB, van der Haegen A, Luminet O, et al. (2014) Personally relevant vs. nationally relevant memories: An intergenerational examination of World War II memories across and within Belgian French-speaking families. Journal of Applied Research in Memory and Cognition 3(4): 280-286. 
United Nations Development Programme (2020) Human development index. Available at: http:/hdr.undp. org/en/content/latest-human-development-index-ranking (accessed 16 February 2021).

van de Bildt J (2015) The quest for legitimacy in postrevolutionary Egypt: Propaganda and controlling narratives. The Journal of the Middle East and Africa 6(3-4): 253-274.

Vázquez C and Páez D (2010) Posttraumatic growth in Spain. In: Weiss T and Berger R (eds) Posttraumatic Growth and Culturally Competent Practice: Lessons Learned from Around the Globe. New Jersey: John Wiley \& Sons, pp.97-112.

Woods J (2011) The 9/11 effect: Toward a social science of the terrorist threat. The Social Science Journal 48(1): 213-233.

Yamashiro JK and Roediger III HL (2019) How we have fallen: Implicit trajectories in collective temporal thought. Memory 27(8): 1158-1166.

\section{Author biographies}

Sarah Y Choi is a PhD Candidate at Massey University in New Zealand. Her main research interests are in the areas of social and cultural psychology, with a focus on collective memory and identity.

James H Liu (刘豁夫) is Professor of Psychology at Massey University in New Zealand. He has been influential in the development of the Asian Association of Social Psychology. His work is in social, cross-cultural, and political psychology, where he has co-authored over 220 publications, and is currently co-Editor-in-Chief of Political Psychology. He specializes in social representations of history and identity politics, as a psychological approach to collective memory. He also has interests in trust, digital influence, and the evolutionary psychology of global consciousness. He is invested in New Confucianism, having absorbed this philosophy for living, and living as an academic from his father, who was a Professor of Philosophy.

Silvia Mari, PhD, is an Associate Professor of Social Psychology at the University of Milano-Bicocca in Italy. Her research interests cover social and political psychology, with a focus mainly on: the implications of lay representations of history and group-based emotions on intergroup relations; attitudes and conspiracy beliefs; effects of collective victimhood in structural conflict; effects of economic crisis and economic inequalities; digital influence on political attitudes. She is an active member of some collaborative international networks and ongoing projects. She serves as Associate Editor of the Journal of Social and Political Psychology.

Ilya E Garber, PhD, Dr. Habil., is a Research Associate at Harvard University in the United States and Professor of Psychology at Saratov State University in Russia (remote position). His research interests are concentrated in two fields: academic research (history of science, philosophy of science, meta-studies) where he published three books devoted to a meta-approach to science, and applied cross-cultural research (social representations of world history, behavioral economics/monetary intelligence, and collaboration in large organizations). He is founder and administrator of the academic international interdisciplinary Facebook group "Methodology and History of Psychology" that unites 17,500+ members from 90+ countries. 